IZA DP No. 9039

Cooperation and Discrimination Within and Across

Language Borders:

Evidence from Children in a Bilingual City

Silvia Angerer

Daniela Glätzle-Rützler

Philipp Lergetporer

Matthias Sutter

May 2015 


\title{
Cooperation and Discrimination Within and Across Language Borders: Evidence from Children in a Bilingual City
}

\author{
Silvia Angerer \\ Institute for Advanced Studies Carinthia \\ Daniela Glätzle-Rützler \\ University of Innsbruck \\ Philipp Lergetporer \\ Ifo Institute, University of Munich \\ Matthias Sutter \\ University of Cologne, University of Innsbruck and IZA
}
Discussion Paper No. 9039
May 2015

IZA
P.O. Box 7240
53072 Bonn
Germany
Phone: $+49-228-3894-0$
Fax: +49-228-3894-180
E-mail: iza@iza.org

\begin{abstract}
Any opinions expressed here are those of the author(s) and not those of IZA. Research published in this series may include views on policy, but the institute itself takes no institutional policy positions. The IZA research network is committed to the IZA Guiding Principles of Research Integrity.

The Institute for the Study of Labor (IZA) in Bonn is a local and virtual international research center and a place of communication between science, politics and business. IZA is an independent nonprofit organization supported by Deutsche Post Foundation. The center is associated with the University of Bonn and offers a stimulating research environment through its international network, workshops and conferences, data service, project support, research visits and doctoral program. IZA engages in (i) original and internationally competitive research in all fields of labor economics, (ii) development of policy concepts, and (iii) dissemination of research results and concepts to the interested public.
\end{abstract}

IZA Discussion Papers often represent preliminary work and are circulated to encourage discussion. Citation of such a paper should account for its provisional character. A revised version may be available directly from the author. 


\section{ABSTRACT \\ Cooperation and Discrimination Within and Across Language Borders: Evidence from Children in a Bilingual City}

We present experimental evidence from a bilingual city in Northern Italy on whether the language spoken by a partner in a prisoner's dilemma game affects behavior and leads to discrimination. Running a framed field experiment with 828 six- to eleven-year old primary school children in the city of Meran, we find that cooperation generally increases with age, but that the gap between cooperation among in-group members and cooperation towards children speaking another language is considerable and increasing with age. This gap is due to both, in-group favoritism and language group discrimination.

JEL Classification: C91, C93, D03

Keywords: cooperation, discrimination, language, children, experiment

Corresponding author:

Matthias Sutter

Department of Economics

University of Cologne

Albertus-Magnus-Platz

D-50923 Cologne

Germany

E-mail: matthias.sutter@uni-koeln.de

\footnotetext{
${ }^{*}$ We are particularly grateful to Jeff Butler, Marc Piopiunik and seminar participants at the European Forum Alpbach Working Group of Young Researchers, the Economic Science Association meetings in Cologne and Tokyo, the Maastricht Behavioral and Experimental Economics Symposium, the Nordic Conference on Behavioral and Experimental Economics in Aarhus, the Mainz International Workshop on Behavioral Economics, Ifo Institute in Munich, EIEF Rome, University of Munich and University of Innsbruck for very helpful comments. We thank Rudolf Meraner from the South Tyrolean State Board of Education (Deutsches Bildungsressort Bereich Innovation und Beratung), the schools' headmasters (Gabriella Kustatscher, Maria Angela Madera, Eva Dora Oberleiter, Brigitte Öttl, Ursula Pulyer, Vally Valbonesi), and the parents of the involved children for making this study possible, and the children for participation. Financial support from the Government of the autonomous province South Tyrol through grant 315/40.3 is gratefully acknowledged.
} 


\section{Introduction}

In-group favoritism and out-group discrimination are "among the most well documented and widely observed phenomen[a] in the social sciences” (Ruffle and Sosis, 2006, p. 148). Evidence for the economic implications of intergroup discrimination is vast and spans from discrimination in labor, housing, credit or consumer markets to political conflict or even social unrest (see, e.g., Arrow, 1998; Darity and Mason, 1998; Ladd, 1998; Yinger, 1998; Fershtman and Gneezy, 2000; Bernhard et al., 2006; Goette et al., 2006; Charness et al., 2007; Chen and Li, 2009; Meier et al., 2014). Discrimination entails potentially large efficiency costs by undermining the provision of public goods when interacting with out-group members (Habyarimana et al., 2007).

Despite the fact that discrimination and its economic implications have been studied in many different societies and based on a multitude of attributes like ethnicity, religion, gender, or language, the development of such behavior in children is still poorly understood. This is unfortunate since a profound understanding thereof is a necessary precondition for designing effective policies which tackle discriminatory behavior before it becomes internalized (Hewstone et al., 2002; Buttelmann and Boehm, 2014), and because recent research shows that cooperation within groups may co-evolve with out-group discrimination (Choi and Bowles, 2007).

In this paper, we investigate in a framed field experiment (Harrison and List, 2004) how intergroup discrimination evolves in childhood. We exploit an almost unique natural setting which allows us to study discrimination based on language group affiliation in Meran, a town with 38,000 inhabitants in the Northern Italian province of South Tyrol (Alto Adige). Virtually $50 \%$ of the citizens of Meran are German-speaking and 50\% Italian-speaking. While citizens of both language groups are not segregated with respect to the area of residence and thus live next-door to one another, schools - as well as most other institutions in the province - are segregated by language (see Section 2 for historical and cultural background information). We present evidence from an incentivized experiment on cooperation with 828 children, aged six to eleven years (grade one to grade five), who either speak Italian or German.

We employ a modified version of a simultaneous prisoner's dilemma game in which the identity of the interaction partner is varied across three different treatments. In one treatment, the interaction partner is from a subject's own school class, in another one from another school where the same language is spoken, though, and in a third treatment the interaction partner is from the other language group. The treatment was indicated by simply stating the name of the 
school (that the interaction partner attends) which is an unambiguous signal about the interaction partner’s language.

Across all age groups, children cooperate significantly more with partners from their own class as compared to partners from a different school, but the same language group. The lowest level of cooperation is always observed when interaction takes place with someone from the other language group. The latter effect turns significant in the later years of primary school only, however, meaning that language discrimination seems to develop gradually. Interestingly, this development goes hand in hand with an increase in the level of cooperation towards ingroup members.

Our paper is related to an increasing literature on the development of cooperative behavior in childhood and adolescence (see, for instance, Fan, 2000; Harbaugh and Krause, 2000; Peters et al., 2004; Sally and Hill, 2006; Alencar, 2008; Cardenas et al., 2014; Lergetporer et al., 2014). Typically, these studies have not investigated how discrimination towards members of different groups develops. One exception in a slightly different context is Fehr et al. (2008). They ran a series of binary dictator games with subjects aged 3 to 8 years in order to study how social preferences and parochialism co-evolve. Implementing one in-group- and one out-group condition (with receivers from the decision-maker's own play group, respectively another play group in kindergarten or school), they find that children act more prosocially towards in-group members and that this bias is most pronounced in their oldest age group of 7/8 year olds. Fehr et al. (2013) apply the same experimental paradigm to subjects aged 8 to 17 years and find that adolescents become less spiteful (more altruistic) towards in-group members from the age of 12/13 years (14/15 years) on.

Our study differs from Fehr et al. $(2008,2013)$ in at least two important dimensions. First, we implement two different out-group conditions in addition to the in-group condition. This allows us to study the development of discrimination across the linguistic divide on top of mere in-group favoritism. In other words, we can measure the influence of language. Second, we focus on cooperative behavior instead of distributional preferences. While both dimensions are related (Andreoni, 1995), they have different implications in the context of intergroup discrimination: Discrimination in dictator games can be rationalized by the decision-maker's pure "taste for discrimination”. In strategic situations like the prisoner's dilemma game, however, ethnic stereotypes are another possible source of discriminative behavior (see Fershtman and Gneezy, 2001). Since experimental evidence suggests that the mere taste for discrimination cannot account for intergroup discrimination in natural environments (see 
Fershtman and Gneezy, 2001; Habyarimana et al., 2007), we investigate the joint effect of both channels and also discuss the role of beliefs for the decision to cooperate.

The rest of the paper is structured as follows. In the next section, we provide a brief account of the historical and cultural background of the autonomous province of South Tyrol (Italy). The experimental design and procedure are introduced in Section 3. Section 4 presents the results and Section 5 concludes the paper.

\section{A brief account of historical background}

Meran is the second largest city in the autonomous province of South Tyrol in the North of today's Italy. This province was part of the Austro-Hungarian Empire for centuries before it was annexed by Italy in the aftermath of World War One and became part of Italy through the treaty of Saint-Germain in 1919. Although South Tyrol had been inhabited by both German and Italian speaking citizens (and a very tiny minority of Ladin-speaking citizens) before 1919, in the interwar-period and early years after World War Two the Italian government promoted the "Italianization" of South Tyrol by (i) declaring Italian the exclusive language in public offices, (ii) closing down the majority of German schools and, (iii) relocating Italians from other parts of Italy to South Tyrol. This led to considerable tensions between both language groups that culminated in a series of terrorist attacks throughout the 1960s by a group called South Tyrolean Liberation Committee. Only in the early 1970s these tensions could be resolved by implementing the Autonomous Statute which guarantees equal rights and access to the public sector to citizens of both language groups (Alcock, 1970). In addition the statute grants the South Tyrolean considerable independence from the national government in Rome with autonomous legislative and executive power in most economic and social matters. The statute also includes several measures intended to guarantee equal rights to the different language groups, such as applying ethnic proportionality rules in public administration and the introduction of three autonomous school boards - each responsible of its own language group.

Today, of about half a million inhabitants in South Tyrol, slightly less than 70\% report German and about 30\% report Italian as their mother tongue. In Meran, 50.5\% of the population speaks German and $49.1 \%$ Italian (with the rest of $0.4 \%$ speaking Ladin). It is noteworthy that within the city of Meran, there is almost no segregation along language lines with respect to the area of residence. Rather, citizens of both language groups live next to each other. Both groups are also predominantly catholic. However, social life is fairly segregated, with different media (like newspapers or TV channels), leisure activities (like different football clubs), and in 
particular schools that either teach in Italian or in German. While the curricula of both types of schools are following the same national regulations and standards, so far there are no schools with bilingual teaching or with an equal representation of Italian- and German-speaking children. Rather, there is either an overwhelming majority of Italian-speaking or of Germanspeaking children attending a particular school. In fact, in our sample of 828 children there are only seven children whose parents speak only German who attend an Italian school, and only 17 children with only Italian-speaking parents attending a German school. Such a degree of segregation is typical for all levels from kindergarten to the completion of high school.

\section{Experimental design and procedure}

\subsection{Design}

Each subject participated in three modified one-shot prisoner's dilemma games (see Figure 1 for the payoff-matrix). In each game, a subject had a new, anonymous partner from the same grade, and this was common knowledge. Both players in each game were endowed with five tokens and had to decide simultaneously how many of the tokens (if any) to send to the partner. Each token sent was doubled. This game resembles the classic binary prisoner's dilemma game since there is a tension between the socially efficient outcome of full cooperation (i.e. sending all tokens) and selfish defection by keeping all tokens.

\section{Figure 1 about here}

The three games differed with respect to the group membership of the partner. In treatment CLASS, the partner was a randomly chosen child from the subject's own class, thus representing an in-group condition as in Fehr et al. (2013) ${ }^{1}$. In treatment SAME-L, the partner was from another school, but spoke the same language as the decision-making child. Finally, in treatment OTHER-L, the partner was again from another school, but spoke the other language (either Italian, if the decision-making child spoke German, or vice versa). ${ }^{2}$ Through our within-

\footnotetext{
${ }^{1}$ Note that a child's primary school class constitutes her most important social group outside the family and that peer interactions in primary school classes are essential in the socialization process (Parsons, 1959). Therefore, it seems natural to define children from the same school class as in-group.

${ }^{2}$ Following previous literature on intergroup discrimination, we employ a within-subject design (see, for instance, Charness et al.'s, 2007, laboratory experiment and the framed field experiment by Falk and Zehnder, 2013). Since we exploit the almost unique natural setting of Meran, the limited number of children in the town rendered the use of a between-subject design infeasible: A between-design would have reduced our observations per treatment to a number which is too low to perform reliable sub-group analyses (for instance, with respect to gender, age- and language groups).
} 
subjects design, we can measure three forms of discrimination based upon different group membership of the partner: pure language group discrimination (comparing SAME-L with OTHER-L), pure in-group favoritism (comparing CLASS with SAME-L) and the joint effect of language group discrimination and in-group favoritism (comparing CLASS with OTHERL).

It is important to stress that the partner's language was not mentioned during the instructions in order to minimize potential experimenter demand effects. Instead, we revealed only the name of the school of the interaction partner, which is an unambiguous indication of the language that children speak in a particular school. ${ }^{3}$ More precisely, we induced the two out-group-treatments by presenting a list of all German, respectively Italian, schools and randomly selected one of the schools, conditional on the treatment (SAME-L or OTHER-L). ${ }^{4}$

The three games were played in random order (see the Appendix for experimental instructions and material). After children had made their three decisions, we asked them how many tokens they expected to receive from the partner in each game (again in random order). The belief elicitation was incentivized with tokens. One randomly selected game was paid out four weeks after the experiment had taken place and tokens were exchanged for fruits, sweets and little presents ${ }^{5}$.

\subsection{Subject pool and procedure}

We conducted our experiment in all fourteen elementary schools in Meran (South Tyrol, Italy) from April to May 2012. It was approved by the Internal Review Board of the University of Innsbruck, the South Tyrolean State Board of Education, the headmasters of all schools, and by the parents of the involved children. In total, we obtained permission from $86 \%$ of parents of all primary school children in Meran to run experiments with their children (which were

\footnotetext{
${ }^{3}$ As a manipulation check, we asked our participants which language they expected their partners to speak after all decisions had been made. 96 (97) percent of our subjects correctly anticipated that partners from schools with German (Italian) names actually speak German (Italian). These shares are statistically indistinguishable across language groups ( $\mathrm{p}>0.1$, McNemar test) and do not differ with respect to age or language group affiliation.

${ }^{4}$ We deliberately chose to pick one of the respective schools (German or Italian) from the set of possible schools in order to avoid that discrimination could be accounted for by discrimination towards residents from lowincome districts. Since children in Meran are almost always assigned to the primary school which is closest to their home, the area of residence of the interaction partner (and not her language group affiliation) could potentially account for observed discrimination. Our procedure minimizes this possibility. Note that in their city-wide trust-game, Falk and Zehnder (2013) found that trustors exhibit less trust towards residents from lowincome districts.

${ }^{5}$ The use of non-monetary incentives is standard for experiments with children in the age groups considered here (see, for instance, Harbaugh and Krause, 2000).
} 
conducted during regular school hours). Of course, participation in the experiment was voluntary for children, but only one child opted out.

Each child was fetched individually from the classroom and brought to a separate room where the experiment was explained face-to-face by one of the experimenters (with some other experimenters explaining the experiment to other children in different corners of the room). The experimenters had to memorize the instructions of the game and explain the game orally (in the mother-tongue of the child) with some visual support. Participants were assured that all choices remained confidential. The duration of the experiment was approximately 20 minutes and it was conducted with pen and paper. In order to guarantee the understanding of the experimental instructions each child had to repeat the rules of the game and the possible consequences of different actions in its own words. In our analysis, we proceed with those 828 German- or Italian-speaking children who were able to repeat the rules of the game correctly (see Table 1). ${ }^{6}$ There were 17 more children whom we exclude from the analysis because they were not able to do so.

\section{Table 1 about here}

We used little presents like sweets (lollipops, small chocolates, candies), fruits (small bags of dried apple slices, nuts and raisins) and other presents (stickers, balloons, pencils, wristbands) which children could get in exchange of their tokens in our "store". The cost of each present was equal to one token. The children were invited to come one by one into the "store" to choose their most preferred reward. As the total earnings of each child were dependent also on the decision of the partner, it was not possible to calculate the exact earnings of the children directly at the end of the experiment. Thus children received their payment (as many pieces of their most preferred reward as the number of tokens they had earned in the experiment) four weeks after the experiment. We paid close attention to maintaining anonymity in all phases of the experiment. ${ }^{7}$ Therefore, the payoffs were handed over in sealed, nontransparent envelopes by a teacher who was not informed about the content of the experiment.

\footnotetext{
${ }^{6}$ A non-negligible share of children in Meran is bilingual (German and Italian). Since this paper studies the development of discrimination between language groups, we excluded 231 children who stated that they speak both languages with their parents from the subsequent analysis.

${ }^{7}$ Lifting anonymity in cooperation experiments with children is particularly problematic, because it has been shown that children who belief that they can be sanctioned for non-cooperation significantly increase their cooperation-rates (Lergetporer et al, 2014). This observation may well extend to informal sanctioning behavior outside the laboratory setting.
} 


\section{Results}

4.1 Non-parametric analysis

Figure 2 shows in panel (A) the number of tokens sent to the partner, separated by treatment and age (where the five age groups coincide with grades 1 to 5 in primary school). The level of cooperation is increasing with age $(\mathrm{p}<0.01$ in each treatment, Cuzick's Wilcoxontype tests for trend), yet there is a clear and consistent ordering across treatments. Across all age groups, cooperation is highest in CLASS, intermediate in SAME-L, and lowest in OTHER$\mathrm{L}(\mathrm{p}<0.01$ in each pairwise comparison, Wilcoxon signed rank tests). In general, the gap between cooperation with in-group-members (in CLASS) and out-group members (in SAME$\mathrm{L}$ and OTHER-L) is getting larger with age, rather than smaller.

\section{Figure 2 about here}

This gap and its magnitude in each age group is shown in Figure 3. The largest differences are found between CLASS and OTHER-L, a comparison that captures the joint effect of differences in language group discrimination and in-group favoritism. This difference is significant in each age group ( $p=0.05$ for $6 / 7$-year olds and $p=0.00$ from age $7 / 8$ on, Wilcoxon signed rank tests). The pure effect of in-group favoritism (holding language constant, i.e., CLASS vs. SAME-L) is somewhat smaller in magnitude, but it is still significant for all but the youngest age cohort ( $\mathrm{p}<0.05$ for age $7 / 8$ on; Wilcoxon signed ranks test). The differences between SAME-L and OTHER-L are smallest and reach statistical significance only in children aged 9/10 years and $10 / 11$ years ( $p=0.02$ and $p=0.00$, respectively; Wilcoxon signed rank tests).

In sum, we see that discrimination towards the other language-group becomes more pronounced with increasing age. There is a positive and (partly weakly) significant age trend in the differences between SAME-L and OTHER-L ( $\mathrm{p}=0.07$, Cuzick's Wilcoxon-type test for trend) and between CLASS and OTHER-L ( $\mathrm{p}=0.03$, Cuzick's Wilcoxon-type test for trend). However, no such trend is detected in the gap between CLASS and SAME-L ( $\mathrm{p}=0.147$, Cuzick’s Wilcoxon-type test for trend).

Figure 3 about here

Figure 2 shows in panel (B) the development of beliefs (about the expected tokens from the interaction partner). Strikingly, children always expect more tokens from their partner than they are, on average, willing to give themselves $(\mathrm{p}<0.05$ in each age group and treatment; 
Wilcoxon signed rank tests). This highlights the fact that a substantial fraction of children have (i) unrealistic beliefs about the behavior of their partner and (ii) are somewhat freeriding on the expected behavior of their partner. Nevertheless, there is a positive correlation between sent tokens and expected tokens $(\mathrm{p}<0.05$ in treatment OTHER-L for 6/7-year olds and $\mathrm{p}<0.01$ in all other treatment-cohort combinations; Spearman rank correlations), indicating that children act conditionally cooperative (Fischbacher et al., 2001).

Comparing panels (A) and (B) in Figure 2 shows that the gap between sent tokens and expected tokens is clearly diminishing as children get older ( $\mathrm{p}=0.00$ in each treatment, Cuzick's Wilcoxon-type test for trend). This means that (i) expectations are getting more realistic and more closely aligned with actual decisions and (ii) freeriding on the partner's expected contribution is less often observed in older children. It is noteworthy that the order of cooperation across treatments, as observed in panel (A) of Figure 2, also holds for beliefs in panel (B). Across all age groups, children expect to receive on average the largest number of tokens from a partner who attends the same class (CLASS), followed by a partner from another school, but within the same language group (SAME-L), and they expect to receive the least from someone from the other language group (OTHER-L) $(p<0.05$ in each pairwise comparison, Wilcoxon signed rank tests). ${ }^{8}$ Given that children seem to condition their level of cooperation on their expectations about the partner's choice, this implies that the differences between treatments are, at least partly, influenced by expectations.

\subsection{Regression analysis}

The patterns of non-parametric results presented above are confirmed in a regression analysis. In Table 2, we present OLS regressions ${ }^{9}$ with the number of tokens sent as the dependent variable, clustered on the individual level. Specification (1) demonstrates that cooperation increases significantly with age in each treatment. Girls send more tokens than boys and so do German-speaking children, compared to their Italian counterparts. The Wald-tests beneath Table 2 show a significant degree of intergroup discrimination and are in line with our non-parametric analysis above: Across all age groups, cooperation is significantly higher in

\footnotetext{
${ }^{8}$ The differences in beliefs between SAME-L and OTHER-L are only significant in the two oldest age cohorts $(\mathrm{p}=0.01$ in both age groups, Wilcoxon signed rank tests). In-group favoritism in beliefs (CLASS vs. SAME-L) is found to be significant from 8/9-years on $(p=0.03, p=0.10$ and $p=0.01$ for children aged 8/9, 9/10 and 10/11 years, respectively, Wilcoxon signed rank tests).

${ }^{9}$ While applied economists disagree on whether models with discrete dependent variables should be estimated with OLS or non-linear approaches, we follow Angrist and Pischke (2008) and estimate our coefficients with OLS. Apart from offering the most efficient estimator and an easy interpretation, OLS is preferable when incorporating interaction terms (Ai and Norton, 2003). Note, however, that our results hold if ordered probit models are employed (see Table A.1 in the Appendix).
} 
CLASS than in OTHER-L, indicating a pronounced joint effect of language group discrimination and in-group favoritism. Furthermore, the pure effect of in-group favoritism (CLASS vs. SAME-L) as well as the net effect of language group discrimination (SAME-L vs. OTHER-L) is highly significant ( $\mathrm{p}<0.01$ in each age group for CLASS vs. SAME-L; $\mathrm{p}<0.1$ for 7/8 year olds and $\mathrm{p}<0.01$ from 8/9 years on for SAME-L vs. OTHER-L). Interestingly, whether or not the decision-maker has friends from the respective other language group has no influence on cooperation rates. In specification (2) we find highly significant positive correlations between beliefs and cooperation, with estimated 0.39 tokens sent more if a child expects the partner to contribute one token more. Adding beliefs does not change the sign or significance of any parameter in Table 2, though.

\section{Table 2 about here}

\section{Conclusion}

This paper studies how cooperation and intergroup discrimination co-evolve in childhood. We exploit the almost unique setting of Meran, a medium-sized town in the autonomous province of South Tyrol (Italy) in which about half of the citizens are German-speaking and the other half Italian-speaking. We present evidence on the development of in-group favoritism and language-group discrimination from an incentivized experiment with 828 primary school children, aged from 6/7 to 10/11 years. Varying the group membership of the interaction partner across treatments in a modified prisoner's dilemma game, we find that children have a marked inclination for in-group favoritism and language group discrimination. With respect to age dynamics, we report two main findings: First, independent of the group membership of the interaction partner, cooperation increases with age. Since cooperation reaps efficiency gains, this looks like a politically welcome finding. Second, however, intergroup discrimination is persistent across all age groups, and seems to increase even in the primary school years.

The driving forces behind discriminatory behavior have been subject to investigation in the recent literature (see, for instance, Fershtman and Gneezy, 2001; Habyarimana et al., 2007). In our case, subjects' beliefs about their partners' choices provide one possible ingredient for discrimination, since children expect more cooperation from in-group members and less so from out-group members, particularly so when they speak a different language. Since children seem to act in a conditionally cooperative way, more pessimistic expectations lead to less cooperation. However, given that the treatment differences in cooperation rates across all age groups remain significant after controlling for beliefs, it is likely that our results are partially 
also driven by some "taste for discrimination”. Besides these main findings, we show that girls exhibit higher cooperation rates than boys and that German-speaking children cooperate more than Italian-speaking children.

Despite the fact that children in Meran learn the other significant language in school, starting from the first grade, language group discrimination seems to get more pronounced with age. One possible explanation for this result might be the fact that the school system in South Tyrol is practically segregating German- and Italian- speaking children by having schools that either teach in German or Italian (except for language classes), but none that teach bilingually. While the latter might have more desirable effects in terms of closing the gap in cooperation rates based on language group discrimination, our results show that learning (and speaking) the same language as the partner does not suffice for overcoming discriminative tendencies.

Based on the evidence presented here, we see several interesting avenues for future research. First, investigating the development of discrimination in children in other natural settings would help to assess whether the effects reported here can be considered as broadly applicable or context-specific. Second, extending the investigation of discrimination in children to other behavioral domains like reciprocity or trust would be a straightforward and interesting exercise. Ultimately, a better understanding of developmental and social origins of discrimination should inform policy makers to design interventions that can diminish the degree of discrimination across different groups in society. 


\section{References}

Ai, C., Norton, E.C., 2003. Interaction terms in logit and probit models. Economics Letters 80, 123-129.

Alcock, E. A., 1970. The History of the South Tyrol Question. London: Michael Joseph.

Alencar, A., Siqueira, J., Yamamoto, M., 2008. Does group size matter? Cheating and cooperation in Brazilian school children. Evolution and Human Behavior 29, 42-48.

Andreoni, J., 1995. Cooperation in public goods experiments: Kindness or confusion? American Economic Review 85, 891-904.

Angrist, J.D., Pischke, J.-S., 2009. Mostly Harmless Econometrics: An Empiricist's Companion. Princeton: Princeton University Press.

Arrow, K., 1998. What has economics to say about racial discrimination? Journal of Economic Perspectives 12, 91-100.

Bernhard, H., Fischbacher, U., Fehr, E, 2006. Parochial altruism in humans. Nature 442, 912915.

Buttelmann, D., Boehm , R., 2014. The ontogeny of the motivation that underlies in-group Bias. Psychological Science 25, 921-927.

Cárdenas, J., Dreber, A., von Essen, E., Ranehill, E., 2014. Gender and cooperation in children: Experiments in Colombia and Sweden. PLoS ONE 9(3), e90923.

Charness, G., Rigotti, L., Rustichini, A., 2007. Individual behavior and group membership. American Economic Review 97, 1340-1352.

Chen, Y., Li, S., 2009. Group identity and social preferences. American Economic Review 99, 431-457.

Choi, J.-K., Bowles, S., 2007. The coevolution of parochial altruism and war. Science 318, 636640.

Darity, W., Mason, P., 1998. Evidence on discrimination in employment: Codes of color, codes of gender. Journal of Economic Perspectives 12, 63-90.

Falk, A., Zehnder, C., 2013. A city-wide experiment on trust discrimination. Journal of Public Economics 100, 15-27.

Fan, C., 2000. Teaching children cooperation - An application of experimental game theory. Journal of Economic Behavior and Organization 41, 191-209.

Fehr, E., Bernhard, H., Rockenbach, B., 2008. Egalitarianism in young children. Nature 454, 1079-1083. 
Fehr, E., Glätzle-Rützler, D., Sutter, M., 2013. The development of egalitarianism, altruism, spite and parochialism in childhood and adolescence. European Economic Review 64, 369-383.

Fershtman, C., Gneezy, U., 2001. Discrimination in a segmented society: An experimental approach. Quarterly Journal of Economics 116, 351-377.

Fischbacher, U., Gächter, S., Fehr, E., 2001. Are people conditional cooperative? Evidence from a public goods experiment. Economics Letters 71, 397-404.

Goette, L., Huffman, D., Meier, S., 2006. The impact of group membership on cooperation and norm enforcement: Evidence using random assignment to real social groups. American Economic Review, Papers and Proceedings, 96, 212-216.

Habyarimana, J., Humphreys, M., Posner, D. N., Weinstein, J. M., 2007. Why does ethnic diversity undermine public goods provision? American Political Science Review 101, 709-725.

Harbaugh, W., Krause, K., 2000. Children’s altruism in public good and dictator experiments. Economic Inquiry 38, 95-109.

Hewstone, M., Rubin, M., Willis, H., 2002. Intergroup Bias. Annual Review of Psychology 53, 575-604.

Harrison, G. W., List, J. A., 2004. Field experiments. Journal of Economic Literature 42, 10091055.

Ladd, H., 1998. Evidence on discrimination in mortgage lending. Journal of Economic Perspectives 12, 41-62.

Lergetporer, P., Angerer, S., Glätzle-Rützler, R., Sutter, M., 2014. Third-party punishment increases cooperation in children through (misaligned) expectations and conditional cooperation. Proceedings of the National Academy of Sciences 111, 6916-6921.

Meier, S., Pierce, L., Vaccaro, A., 2014. Trust and in-group favoritism in a culture of crime. IZA Discussion Paper 8169.

Parsons, T., 1959. The school class as a social system: Some of its functions in American Society. Harvard Educational Review 29, 297-318.

Peters, H., Ünür, A., Clark, J., Schulze, W., 2004. Free-riding and the provision of public goods in the family: A laboratory experiment. International Economic Review 45, 283-299.

Ruffle, B.J. and Sosis, R., 2005. Cooperation and the in-group-out-group bias: A field test on Israeli kibbutz members and city residents. Journal of Economic Behavior and Organization 60, 147-163. 
Sally, D., Hill. E., 2006. The development of interpersonal strategy: Autism, theory-of-mind, cooperation and fairness. Journal of Economic Psychology 27, 73-97.

Yinger, J., 1998. Evidence on discrimination in consumer markets. Journal of Economic Perspectives 12, 23-40. 
Figure 1. Payoff-matrix of the modified one-shot prisoner's dilemma game.

Player 2

\begin{tabular}{|c|c|c|c|c|c|c|}
\hline Tokens sent & $\mathbf{0}$ & $\mathbf{1}$ & $\mathbf{2}$ & $\mathbf{3}$ & $\mathbf{4}$ & $\mathbf{5}$ \\
\hline $\mathbf{0}$ & 5,5 & 7,4 & 9,3 & 11,2 & 13,1 & 15,0 \\
\hline $\mathbf{1}$ & 4,7 & 6,6 & 8,5 & 10,4 & 12,3 & 14,2 \\
\hline $\mathbf{2}$ & 3,9 & 5,8 & 7,7 & 9,6 & 11,5 & 13,4 \\
\hline $\mathbf{3}$ & 2,11 & 4,10 & 6,9 & 8,8 & 10,7 & 12,6 \\
\hline $\mathbf{4}$ & 1,13 & 3,12 & 5,11 & 7,10 & 9,9 & 11,8 \\
\hline $\mathbf{5}$ & 0,15 & 2,14 & 4,13 & 6,12 & 8,11 & 10,10 \\
\hline
\end{tabular}

(The first number in each cell indicates the payoff for player 1, the second number the payoff for player 2.)

Figure 2: (A) Average tokens sent by age and treatment. (B) Average beliefs about the number of tokens sent by the partner. ( $N=828$ subjects)

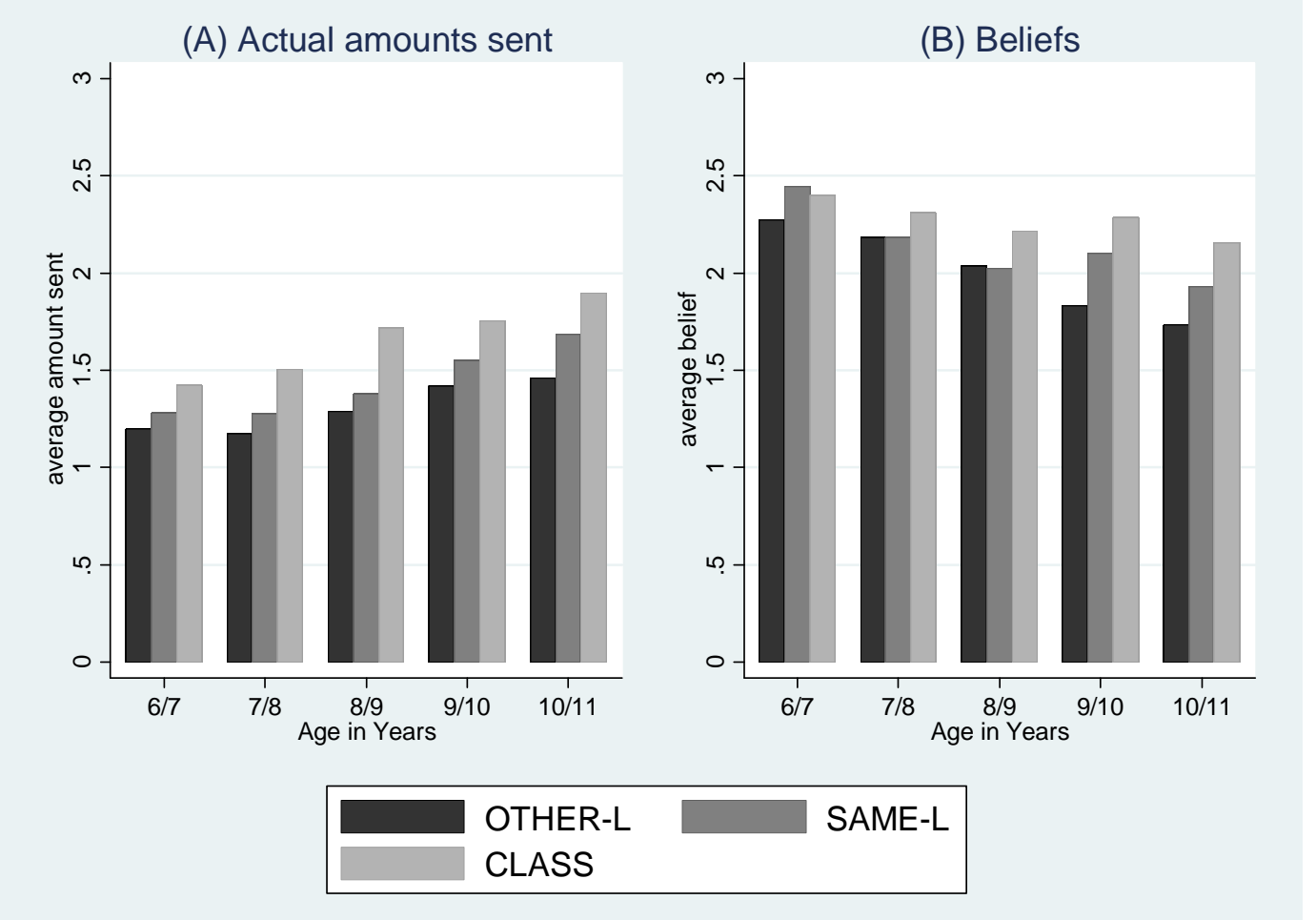


Figure 3: Average discrimination by age ( $N=828$ subjects).

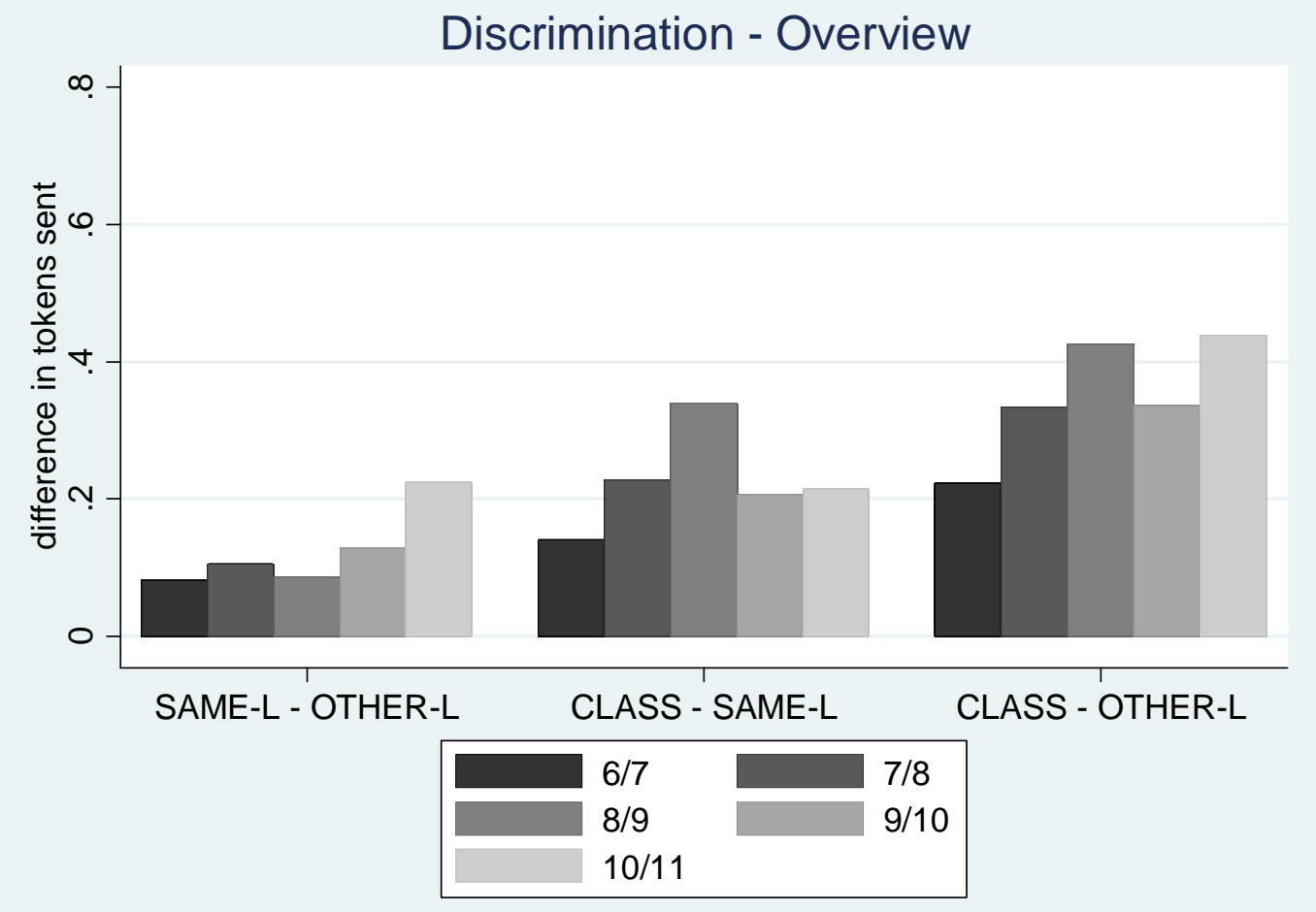


Table 1. Number of monolingual subjects participating in the experiment, by age, language and gender (number of male participants in parenthesis)

\begin{tabular}{lccc}
\hline \hline Age (in years) & Italian & German & Total \\
\hline 6/7 years & $73(40)$ & $62(39)$ & $135(79)$ \\
$7 / 8$ years & $88(55)$ & $92(51)$ & $180(106)$ \\
8/9 years & $82(50)$ & $80(37)$ & $162(87)$ \\
$9 / 10$ years & $88(45)$ & $67(41)$ & $155(86)$ \\
10/11 years & $86(39)$ & $110(54)$ & $196(93)$ \\
\hline ALL & $\mathbf{4 1 7}(\mathbf{2 2 9})$ & $\mathbf{4 1 1}(\mathbf{2 2 1})$ & $\mathbf{8 2 8}(\mathbf{4 5 1})$ \\
\hline \hline Each subject was asked to repeat the instructions in own words in order to check for understanding. 17 \\
additional subjects were not able to do so properly, and we exclude them from the analysis. Moreover, \\
231 bilingual children (German and Italian) were excluded.
\end{tabular}


Table 2: OLS Regressions of the number of tokens sent in each of the three treatments.

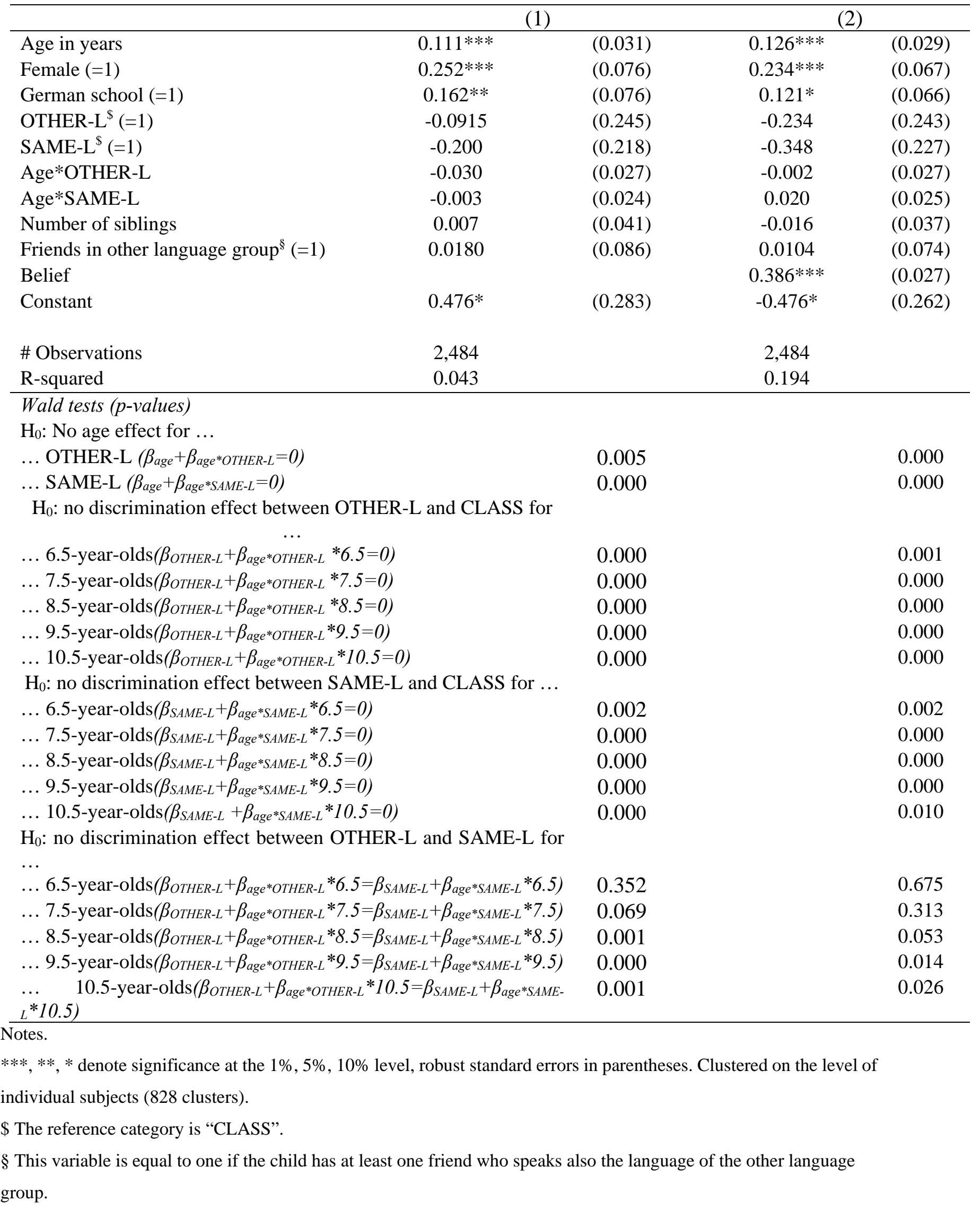




\section{Appendix (not intended for publication)}

Table A.1: Ordered Probit Regressions of the number of tokens sent in each of the three treatments.

\begin{tabular}{|c|c|c|c|c|}
\hline & \multicolumn{2}{|c|}{ (1) } & \multicolumn{2}{|c|}{ (2) } \\
\hline Age in years & $0.102 * * *$ & $(0.026)$ & $0.128 * * *$ & $(0.027)$ \\
\hline Female (=1) & $0.244 * * *$ & $(0.064)$ & $0.256 * * *$ & $(0.061)$ \\
\hline German school $(=1)$ & $0.158 * *$ & $(0.064)$ & $0.137 * *$ & $(0.061)$ \\
\hline OTHER-L $^{\$}(=1)$ & -0.171 & $(0.218)$ & -0.291 & $(0.238)$ \\
\hline SAME-L $^{\$}(=1)$ & -0.228 & $(0.188)$ & $-0.376^{*}$ & $(0.214)$ \\
\hline Age*OTHER-L & -0.015 & $(0.024)$ & 0.006 & $(0.026)$ \\
\hline Age*SAME-L & 0.005 & $(0.020)$ & 0.025 & $(0.023)$ \\
\hline Number of siblings & 0.000 & $(0.034)$ & -0.021 & $(0.035)$ \\
\hline Friends in other language group ${ }^{\S}(=1)$ & 0.025 & $(0.070)$ & 0.021 & $(0.067)$ \\
\hline $\begin{array}{l}\text { Belief } \\
\text { cut } 1\end{array}$ & & & $0.354 * * *$ & $(0.026)$ \\
\hline $\begin{array}{l}\text { Constant } \\
\text { cut } 2\end{array}$ & 0.251 & $(0.234)$ & $1.167 * * *$ & $(0.245)$ \\
\hline $\begin{array}{l}\text { Constant } \\
\text { cut } 3\end{array}$ & $1.134 * * *$ & $(0.237)$ & $2.122 * * *$ & $(0.249)$ \\
\hline $\begin{array}{l}\text { Constant } \\
\text { cut } 4\end{array}$ & $1.850 * * *$ & $(0.243)$ & $2.917 * * *$ & $(0.254)$ \\
\hline $\begin{array}{l}\text { Constant } \\
\text { cut } 5\end{array}$ & $2.430 * * *$ & $(0.252)$ & $3.572 * * *$ & $(0.265)$ \\
\hline Constant & $2.774 * * *$ & $(0.257)$ & $3.963 * * *$ & $(0.273)$ \\
\hline \# Observations & 2,484 & & 2,484 & \\
\hline Pseudo R-squared & 0.018 & & 0.071 & \\
\hline
\end{tabular}

Wald tests ( $p$-values)

$\mathrm{H}_{0}$ : No age effect for ...

... OTHER-L $\left(\beta_{\text {age }}+\beta_{\text {age } * \text { OTHER-L }}=0\right)$

0.001

0.000

... SAME-L $\left(\beta_{\text {age }}+\beta_{\text {age } * \text { SAME-L }}=0\right)$

0.000

0.000

$\mathrm{H}_{0}$ : no discrimination effect between OTHER-L and CLASS for ...

$\ldots$ 6.5-year-olds $\left(\beta_{\text {OTHER-L }}+\beta_{\text {age }}\right.$ OTHER-L $\left.* 6.5=0\right)$

0.000

0.001

$\ldots$ 7.5-year-olds $\left(\beta_{\text {OTHER-L }}+\beta_{\text {age }}\right.$ OTHER-L $\left.* 7.5=0\right)$

0.000

0.000

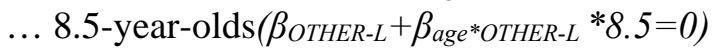

0.000

0.000

... 9.5-year-olds $\left(\beta_{\text {OTHER-L }}+\beta_{\text {age }}\right.$ OTHER-L $\left.* 9.5=0\right)$

0.000

0.000

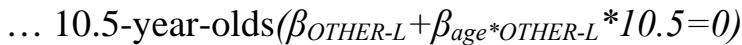

0.000

0.000

$\mathrm{H}_{0}$ : no discrimination effect between SAME-L and CLASS for ...

$\ldots$ 6.5-year-olds $\left(\beta_{\text {SAME-L }}+\beta_{\text {age } * \text { SAME-L }} * 6.5=0\right)$

0.001

0.002

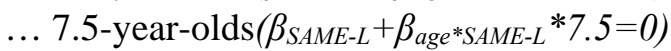

0.000

0.000

$\ldots$ 8.5-year-olds $\left(\beta_{\text {SAME-L }}+\beta_{\text {age } * \text { SAME-L }} * 8.5=0\right)$

0.000

0.000

$\ldots$ 9.5-year-olds $\left(\beta_{\text {SAME-L }}+\beta_{\text {age } * \text { SAME-L }} * 9.5=0\right)$

0.000

0.000

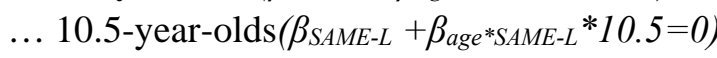

0.000

0.021

$\mathrm{H}_{0}$ : no discrimination effect between OTHER-L and SAME-L for ...

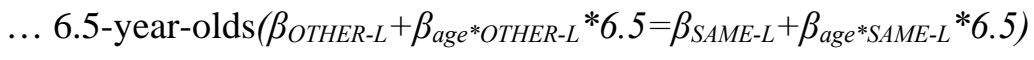

0.302

0.616

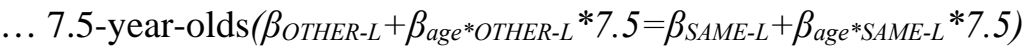

0.067

0.296

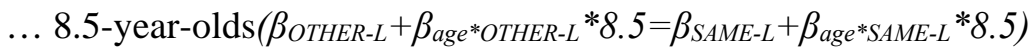

0.002

0.050

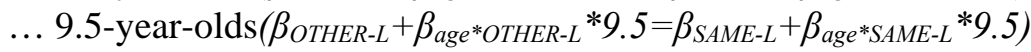

0.000

0.008 
Notes.

***, **, * denote significance at the $1 \%, 5 \%, 10 \%$ level, robust standard errors in parentheses. Clustered on the level of individual subjects (828 clusters).

$\$$ The reference category is "CLASS".

$\S$ This variable is equal to one if the child has at least one friend who speaks also the language of the other language group. 


\section{Experimental Instructions}

Instructions are translated from German, respectively Italian, into English. Instructions were explained individually to each child in his/her mother tongue by one of the experimenters.

\section{General instructions for the assistant are italicized}

Hello, my name is XY. The participation in this game is voluntary. Do you want to participate? (write down the answer: if child wants to participate go on with the instructions; if child does not want to participate then bring the child back to the classroom). In this game you can earn tokens. With these tokens you can buy little presents in our shop. Today all presents cost 1 token. At the end of the game you can choose your favorite present and you will get as many pieces of your favorite present as you earned tokens in the game. Could you please repeat what I have told you so far in your own words? (The following points have to be repeated: (i) the child can earn tokens and exchange them for presents (ii) all presents cost 1 token (iii) the child can choose the favorite present and get as many pieces of the favorite present as tokens earned in the game).

In this game you can send tokens to another child. Here you can see 4 meeples: a yellow meeple, a green meeple, a blue meeple and a red meeple. (meeples are placed in front of the participant) You are the yellow meeple (point at the yellow meeple). The green, blue and red meeple represent your partners in this game and are randomly selected children. It may be a girl or a boy. The green partner is a child who attends the same grade like you but goes to one of these schools here in Meran (place green meeple on the green school-card with German school names on it), but not to your own school. (This needs to be adapted in Italian schools.) Could you please read the names of the schools your partner could be selected from? (let the child read the school names) The blue partner is a child who attends the same grade like you but goes to one of these schools here in Meran (place blue meeple on the blue school-card with Italian school names on it). Could you please read the names of the schools your partner could be selected from? (let the child read the school names) The red partner is a child from your class (place red meeple on red card). You don’t know who exactly you are playing with. This is a secret. The only thing you know is that the green and the blue partner are in the same grade as you, that they go to one of these schools here in Meran and that your red partner is in the same class as you. Your partners do not know who exactly you are. Could you please repeat what I have told you so far in your own words? (The following points have to be repeated: (i) the participant is the yellow meeple (ii) the participant plays with 3 partners (iii) the partner with 
the green meeple attends one of the schools listed on the green school-card; the child should repeat some of the names on the card (iv) the partner with the blue meeple attends one of the schools listed on the blue school-card; the child should repeat some of the names on the card (v) the partner with the red meeple attends the same class as the participant (vi) all partners are of the same age as the participant (vii) the partners can be male or female (viii) the participant receives no other information on the partners (ix) the partners do not know the identity of the child; if the participant does not repeat all the points alone, then ask questions). The game works as follows:

(The order of presentation of the green/blue/red partner is randomly assigned to each child. Decision sheet with green partner is placed in front of the child; yellow and green meeples with school cards are placed at the right and the left hand side of the decision sheet respectively; blue and red meeples are layed aside.) As you know, you are the yellow meeple. On this decision sheet you can see also a green meeple (point to the green meeple). This means that you are now playing with your green partner. Each of you gets five tokens at the beginning (five tokens are placed in front of the yellow and green meeple) and each of you has to decide how many tokens you want to take for yourself and how many tokens you want to send to your partner. It is very important that the child who you can send tokens to can also send tokens to you. Look, I have tokens too (tokens are placed in front of the assistant). For each token sent, I will add another token. I will do this for each token you send to your partner, but also for each token that your partner sends to you. On this decision sheet you have to decide, whether you would like to send ZERO, ONE, TWO, THREE, FOUR or FIVE of your tokens to your green partner (when listing the possibilities of decision making point at the respective box). If you want to send for example TWO tokens, than you have to tick the box here (point at the box). In that case you send two tokens away (two tokens from the yellow meeple are pushed away), I will add two more tokens (two tokens are added to the other two tokens) and your green partner gets four tokens in addition (four tokens are placed next to the tokens of the green partner). Can you tell me which box you have to tick if you would like to send FOUR tokens to your partner? (reallocate the tokens to get the original allocation). And what happens if you send FOUR tokens? (the participant has to explain: (i) participant sends four tokens away (ii) assistant adds four more tokens; (iii) partner gets eight tokens additionally) And what happens if you send nothing? (the participant has to explain: (i) participant sends no tokens away (ii) assistant adds nothing; (iii) partner gets nothing in addition) The green partner has exactly the same decision to make: he also has to decide whether to send ZERO, ONE, TWO, THREE, FOUR or FIVE tokens to you. Can you tell me, what happens if your partner sends THREE tokens to 
you? (the participant has to explain: (i) partner sends three tokens away (ii) assistant adds three more tokens; (iii) participant gets six tokens in addition). Do you know how many tokens your green partner sends to you? (Answer: No) The same is true for your green partner; he also does not know how many tokens you sent to him when he is upon to decide.

Could you please repeat the rules concerning the tokens in your own words? (participant has to repeat: (i) the participant can send between zero and five tokens to the partner (ii) the tokens are doubled (iii) the partner has to make the same decision and the tokens sent by the partner are also doubled (iv) at the time of the decision no one knows how many tokens the partner sent)

You know you have three partners, a green partner, a blue partner and a red partner. On this decision sheet (decision sheet with blue partner is placed onto the green decision sheet) you can see a blue meeple (point at the blue meeple). This means that you are now playing with your blue partner. The game works exactly the same as with your green partner. The only difference is that now you play with your blue partner. When you are playing with your red partner (decision sheet with red partner is placed onto the blue decision sheet), the game works exactly the same as with your green and blue partner. The only difference is that now you play with your red partner.

At the end of the game you will not receive the tokens for all three decision sheets but only for a single decision sheet. This means that only one out of the three decision sheets is played and paid out for real. Which decision sheet is played and paid out will be drawn by lot.

This works exactly as follows.

I will mingle the three decision sheets under the table and then you can draw one decision sheet. The drawn decision sheet is the one that is played at the end and you will get only the tokens of this decision sheet; the other two decision sheets are no longer valid.

We don't know yet how many tokens you earn in this game. You receive the tokens that you keep for yourself and the tokens that your partner sends to you. Since we don't know yet how many tokens your partner will send to you, you will receive the presents not today, but in four weeks.

Your partner really exists and just like you your partner also can buy presents with the tokens he earns. Can you please repeat the part concerning which sheet is implemented for payment and how you get your presents in your own words? (Participant has to repeat: (i) only one decision sheet is played and paid out; (ii) the participant gets the presents in four weeks from now; (iii) the partner can also buy presents with the tokens earned). 
It is very important that your decisions are secret. The other children will never know how many tokens you sent. This is your secret.

Now you can make your decisions. Please start with your green partner - your green partner attends one of these schools in Meran (point at the green school card with German school names and at the green decision sheet lying to the left from the participant's perspective). Then fill in the decision sheet with your blue partner - your blue partner attends one of these schools here in Meran (point at the school card with Italian school names and the blue decision sheet lying centered). And then fill in the decision sheet with your red partner - your red partner is a child from your class (point at the red decision sheet lying to the right hand side from the participant's perspective). Please take as much time as you need for your decisions. I will turn around in the meantime so that you are not disturbed. Call me when you are ready (give the participant the pen and turn around; when participant calls, turn towards the participant).

(After the decisions the assistant has to check the decision sheets for completeness. If something is incomplete, ask participant to take the missing decision).

Thank you for your decisions. Now I have some questions. How many tokens do you think does your green, blue and red partner send to you? If in the drawn part your guess is correct you will get a bonus token. If your guess is not correct, you don't get a bonus token. How many tokens do you think does your green partner send to you? (note down) How many tokens do you think does your blue partner send to you? (note down) How many tokens do you think does your red partner send to you? (note down)

What do we have to do next? Exactly, we have to decide which of the three decision sheets is played and paid out. I mingle the three decision sheets under the table and now you can draw one sheet. (Mingle the decision sheets and let the child draw one decision sheet) You have drawn the \{color\} sheet, meaning that this sheet is paid out and that you play with your \{color partner. You will learn in four weeks when you get the envelope with your presents how many presents you get in total. 
Photos
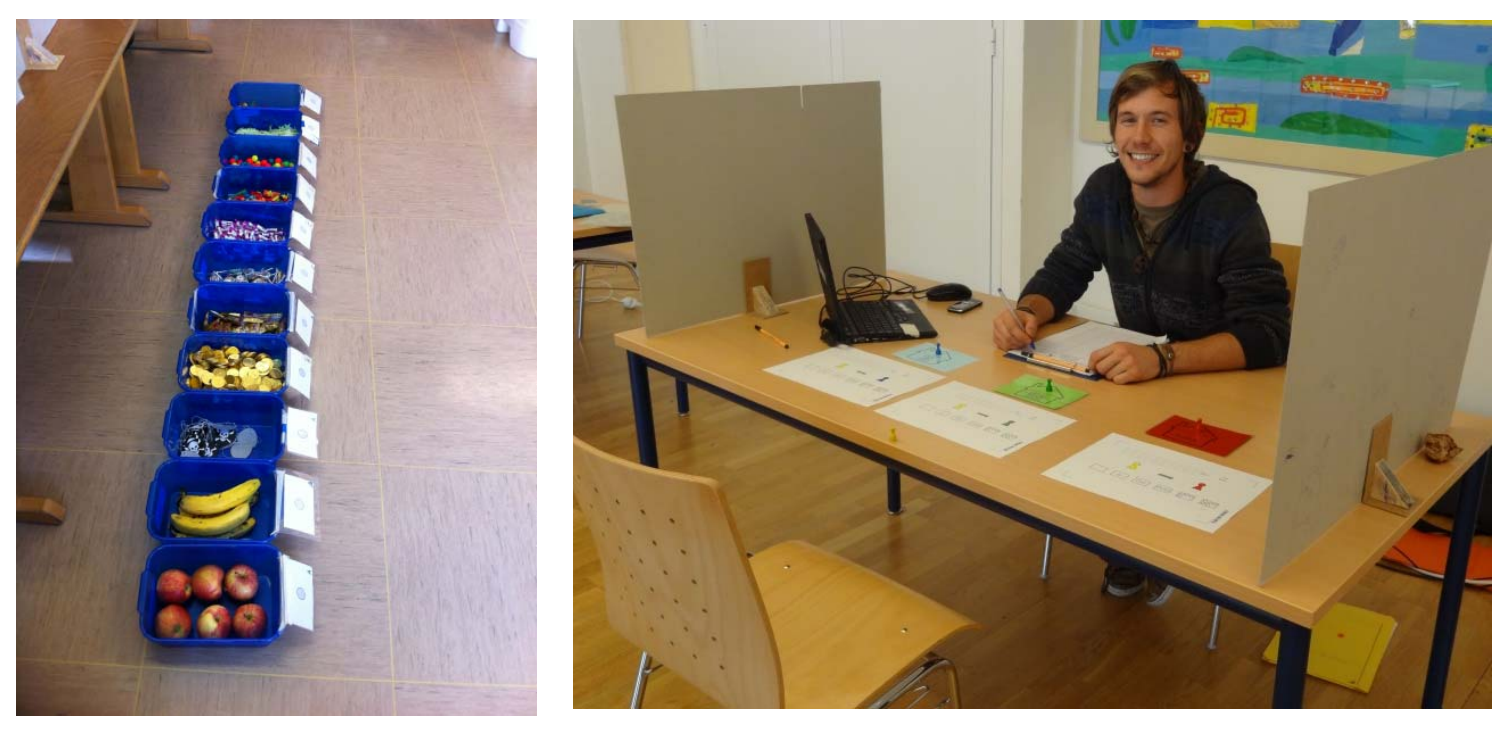


\section{Decision sheet}

$\begin{array}{llllllllll}\mathbf{0} & \mathbf{1} & \mathbf{2} & \mathbf{3} & \mathbf{4} & \mathbf{5} & \mathbf{6} & \mathbf{7} & \mathbf{8} & \mathbf{9} \\ \square & \square & \square & \square & \square & \square & \square & \square & \square & \square \\ \square & \square & \square & \square & \square & \square & \square & \square & \square & \square \\ \square & \square & \square & \square & \square & \square & \square & \square & \square & \square \\ \square & \square & \square & \square & \square & \square & \square & \square & \square & \square\end{array}$

K.:

Punkte:

Code:

Klasse:
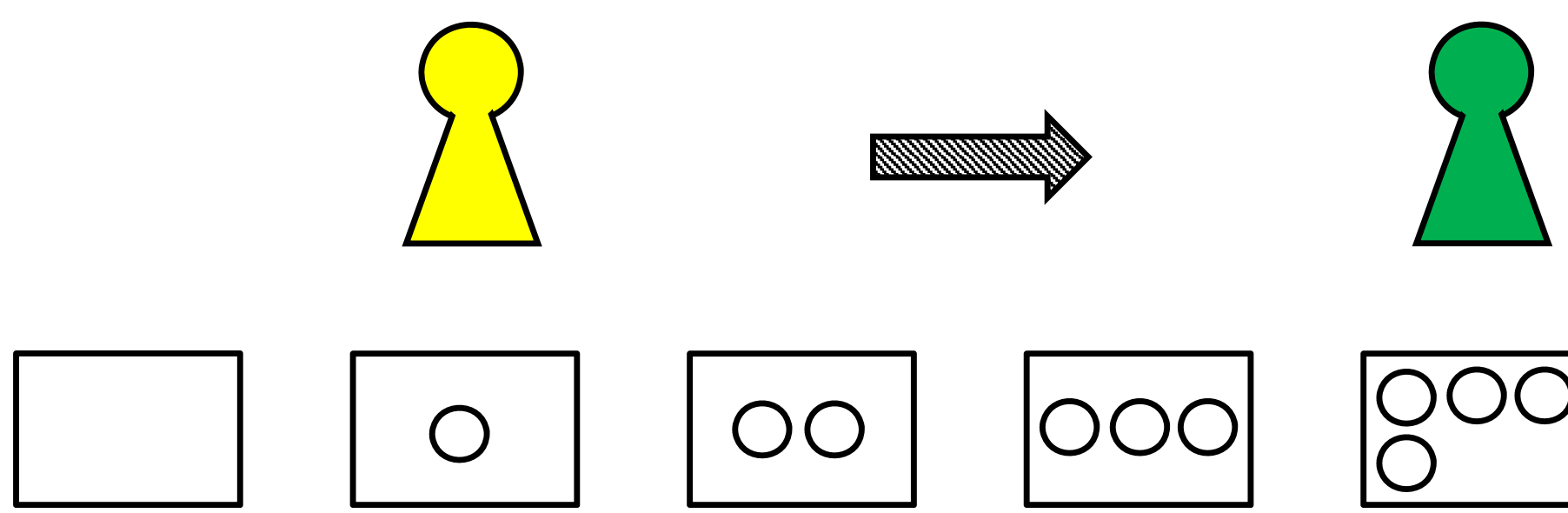

000

800

800

$\square$

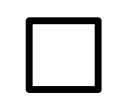

$\square$

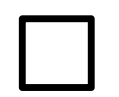

$\square$ 